\title{
Key Problems of Complex Topics in Mathematics as the Basis of Teaching Methods in the Conditions of Self-Education
}

\author{
Natalia A. Zelenina ${ }^{1 *}$, Nadezhda V. Telegina ${ }^{2}$, Gennadi B. Pronchev ${ }^{3}$, Roza I. Yagudina ${ }^{4}$, \\ Farid M. Galimov ${ }^{5}$, Elena V. Slepneva ${ }^{6}$ \\ 1 Vyatka State University, Kirov, RUSSIA \\ ${ }^{2}$ Kazan (Volga region) Federal University, Kazan, RUSSIA \\ 3 Lomonosov Moscow State University, Moscow, RUSSIA \\ ${ }^{4}$ I.M. Sechenov First Moscow State Medical University (Sechenov University), Moscow, RUSSIA \\ ${ }^{5}$ Kazan National Research Technical University named after A. N. Tupolev - KAI, Kazan, RUSSIA \\ ${ }^{6}$ Kazan National Research Technological University, Kazan, RUSSIA
}

Received 4 March 2021 - Accepted 8 June 2021

\begin{abstract}
Ensuring a high quality of teaching mathematics to students is inextricably linked with teaching how to solve creative mathematical problems. These problems traditionally include tasks of high educational, developmental and diagnostic value. Teaching how to solve such problems allows training graduates with the highest level of the subject knowledge. The problem under study is relevant due to the need to form students' ability to solve problems with parameters in order to achieve high results in mathematics, intellectual and personal growth. The problem has a new meaning during temporary distance learning, emphasizing the need to create educational and methodological materials that allow students to organize self-education on complex topics in mathematics. The purpose of this research is to develop and describe a teaching methodology for solving problems with parameters based on the allocation of basic (key) problems. The authors have developed a methodology for constructing a system of tasks based on systematizing the theoretical and task material, highlighting students' basic knowledge and skills, describing the intra- and inter-subject connections of the topic "Equation of a circle in tasks with parameters". This methodology includes a typology of problems with parameters containing the equation of a circle, a substantiated description of the system of basic (key) problems, the role and content of the propaedeutic stage of teaching. The materials have passed multi-stage approbation and shown their consistency in achieving high results in mathematics. They can help teachers to prepare lessons and extracurricular activities, authors to provide teaching aids for students and teachers, and serve as the basis for a special course for students of pedagogical universities.
\end{abstract}

Keywords: teaching mathematics, tasks with parameters, basic (key) tasks, teaching methods of mathematics, equation of a circle

\section{INTRODUCTION}

\section{The Relevance of the Problem}

The modern stage of mathematics education requires modern students to be active in acquiring knowledge and be able to use it in life, further education or professional activity (The concept of the development of mathematical education in the Russian Federation,
2013). An education system focused on attracting students who are capable and show interest in mathematics to solve problems of a creative research nature can facilitate the fulfillment of this requirement (Galiullina, 2018). According to many mathematicians, teachers and methodologists, tasks with parameters have significant potential. Practice shows that teachers use these tasks in the process of teaching mathematics by the systematic inclusion in the materials of lessons on

(c) 2021 by the authors; licensee Modestum. This article is an open access article distributed under the terms and conditions of the Creative Commons Attribution License (http://creativecommons.org/licenses/by/4.0/). 


\section{Contribution to the literature}

- The authors suggest a methodology for teaching students to solve problems with parameters, based on the allocation of the basic (key) problems of the topic and their application in solving a specially designed system of problems. This allows to reveal the close intra-and inter-subject connections of the material of the topic "Equation of a circle in tasks with parameters" and to realize the significant teaching and creative potential of these tasks.

- The authors reveal the role, substantiate goals and objectives, and describe the content and methods of implementation of the propaedeutic stage of teaching students to solve problems with parameters including the equation of a circle.

- The authors present didactic materials for studying the topic "Equation of a circle in tasks with parameters", compiled on the basis of the typology of tasks with the allocation of basic (key) problems. The materials have methodological instructions and comments and can be used for organizing students' self-education.

various topics of the school mathematics course or through a system of special courses. The first way is implemented in specialized physics and mathematics schools and classes, the second option is met in usual educational institutions and is more common. But results of students' final certification show a low productivity of special courses (Boukhanov et al., 2019; Zelenina \& Krutikhina, 2018, 2021; Zelenina \& Nosova, 2020). One reason is the insufficient elaboration of the methodology for organizing such classes as students often solve a certain set of randomly selected tasks there. The systematic formation of educational, methodological and didactic support for students' activities is becoming relevant. First of all, it is the search and methodological processing of the content of the studied material. The task is to provide the mathematics teacher with teaching materials of the necessary level and to make the material understandable for the student, easily assimilated, with a clear structure. This problem has on a special meaning under the conditions of restrictive measures connected with the epidemiological situation of the last two years, when there is an urgent need for students' self-education. The purpose of this study is to show that a special system of tasks with parameters on various topics in mathematics on the basis of the allocation of basic (key) tasks, promotes a conscious, deep and lasting assimilation of knowledge, makes it possible to effectively organize student's selfeducation (Zharko, 2020). Teachers implement the developed technique when studying the topic "Equation of a circle in tasks with parameters". The choice of the topic is determined by the following factors. Firstly, these tasks are traditionally present in casebooks, including competition ones. According to the control and measuring materials of the unified state exam for 2009-2020, the equation of a circle was a part of the problem statement with a parameter in six cases. It emphasizes the value of solving such problems. Secondly, the equation of a circle in the school mathematics course is met only when studying the elements of analytical geometry of a plane. It makes students think of a circle as an exclusively geometric object. Such views are extremely narrow and unidirectional. It is difficult for students without some experience to rethink the circle in terms of other mathematical concepts, to include this object in new connections. Thirdly, the analysis of the problem material has shown a wide variety of combinations of the equation of a circle with other mathematical objects, which makes it possible to establish strong intra- and intersubjective connections of the material and consider it as an important factor in mathematical development.

\section{Research Goals and Objectives}

The purpose of the study is to create educational, methodological and didactic materials for teachers and students on the basis of identifying basic (key) tasks on the topic "Equation of a circle in tasks with parameters" as a means of achieving high results in mathematics during the conditions of self-education due to unfavorable epidemiological situation and distance learning. The main tasks of the research are: to study the role and place of tasks with parameters, including the equation of a circle in students' mathematical education; to analyze the problem material and draw up a typology of tasks with parameters containing the equation of a circle; to select the basis of the typology of key tasks with parameters; to describe the propaedeutic stage of teaching students the topic "Equation of a circle in tasks with parameters"; to study possibilities of using the developed methodology in students' self-education.

\section{LITERATURE REVIEW}

Teachers have used tasks with parameters as a means of teaching mathematics at a high, creative level for more than 40 years. Yastrebinetskiy (1986), Shestakov and Yurchenko (1993), Golubev (2007), etc. have made a great contribution to an extensive bank of such tasks. They provide a wide variety of equations, inequalities and their systems with parameters with examples of their solution, highlighting techniques and methods of solution. However, it is often difficult to work with such material for a teacher and a student who are studying 
approaches to solving problems with parameters. Bashmakov (1976), Vazhenin (1997), Dalinger (1999), Dorofeev (1983), Litvinenko and Mordkovich (1983), etc. have studied the role of tasks with parameters in teaching mathematics, as well as concepts associated with their solution. The authors note the research potential of such tasks, contributing to the assimilation of the scientific foundations of mathematics. Tasks with parameters, in their opinion, contribute to the formation of a high logical culture and creative personality traits. Golubev (1991), Olekhnik et al. (1992), Dorofeev et al. (1999), Modenov (2002), Sergeev (2005), Kozko and Chirsky (2007), Kozhukhov and Kozhukhova (2010a, 2010b), Swetz and Chi (1983), etc. emphasize the importance and great diagnostic value of such tasks for final certification and competitive selection procedures. Manuals for applicants to universities and materials for the state final certification have tasks with parameters. According to the authors, these tasks make it possible to identify graduates who are most capable of studying mathematics and ready to get higher education related to deep study of the subject. Therefore, it is quite natural that many researchers in the field of methods of teaching mathematics consider issues of teaching students to solve tasks with parameters to be important. Thus, Markov (1970), Modenov (2007), Koryanov and Prokofiev (2011), Karasev and Levshina (2012), Zdorovenko et al. (2016), Zdorvenko and Zelenina (2018) study methodology of teaching graphic methods for solving tasks with parameters. The authors, relying on their great teaching experience, note that many students prefer graphic methods of solution to analytical ones as they are visual and simpler and formulate methodological recommendations for teaching. Tokareva and Zelenina (2016), Zakirova et al. (2019), Arcavi (2003), Bhagat and Chang (2015), Al-Hilli (2019), Wassie and Zergaw (2019), etc. consider possibilities of various software tools to facilitate the search for solutions to complex problems of elementary mathematics. Tolpekina (2002), Shivrinskaya (2002), Aryutkina (2002), Miroshin (2008), etc. have formulated methodological recommendations on certain issues of teaching students to solve tasks with parameters. However, we should note that the presented material is either too general in nature, or touches some narrow issues of teaching methods for solving tasks with parameters. It disorients the teacher's work and demotivates the student's activity, since processing a large amount of information in order to achieve a logically built and complete system of studying the material is time-consuming. This problem is especially urgent during distance learning due to the epidemiological situation and emphasizes the need to create teaching materials suitable for both the teacher and the student from the point of self-education. Therefore, the idea of constructing blocks of educational material based on the allocation of basic (key) tasks is relevant. Khazankin (1991, 2000) has developed this technique and then Zilberberg (1988, 1995), Halomizer (1987), Viranovskaya (2008) described and successfully tested it. The long-term high results of teaching mathematics to the students indicate the effectiveness of the above-mentioned methodology. Rozov points out his approach to basic (key) problems in teaching mathematics in different terms, defining the "maximum basis in the space of problems", the assimilation of which ... will allow a "mass student" ... to have favorable conditions for solving any other problems on this topic (or several topics)" (Rozov, 1997). Sharygin (2000) distinguishes a set of so-called key problems that are useful in methodological terms, dividing them into two groups - basic tasks-facts and basic tasks-methods. According to Sharygin, increasing the level of the student's geometric training requires mastering a certain number of basic tasks. Osipenko and Statsevichute (2010) use key tasks as a means of improving the quality of assimilation of planimetry knowledge. Kovaleva and Dyumina (2009) present the principle of constructing systems of tasks by the "key" method. Klekovkin and Maksyutin (2009) consider the use of key problems in teaching mathematics to be of great importance. Ostanov et al. (2018) emphasize the important role of key tasks in systematization of educational material, establishing links between different sections of mathematics. Let us note that methodological studies devoted to using basic (key) problems in the process of teaching mathematics are carried out on geometric material. This is quite justified, since geometry is traditionally difficult for understanding and mastering. However, tasks with parameters have no less potential for the development of the above-mentioned methodology. The systematization of the task material and the design of the training content based on the allocation of basic (key) tasks allow to organize studying this material most effectively, including self-education.

\section{MATERIALS AND METHODS}

\section{Theoretical Foundations of the Research}

The theoretical and mathematical basis for teaching to solve problems with parameters which include the equation of a circle consider questions related to the analytical specification of a circle and canonical equations, the relative position of two circles on a plane, the relative position of a circle and a straight line on a plane, finding the distance between two points of the coordinate plane, finding the distance from a point to a straight line on the coordinate plane, examining the number of roots of a quadratic equation depending on the sign of the discriminant, transforming the plane (parallel translation, rotation). The theoretical and methodological basis of the research is the methodology of teaching mathematics to students through tasks (Kolyagin, 1977; Krupich, 1995; Sarantsev, 1995, 2002) as 
students' main activity in mathematics class. According to this methodology, teachers use specially designed task systems to successfully achieve teaching goals. High results can be achieved if the work with such tasks allows to generalize and systematize students' knowledge; demonstrate intra-subject connections between concepts and facts used in the process of solving problems; carry out the transfer of existing knowledge to a new problem situation; include students in the research process. The teaching methodology for solving mathematical problems, based on the allocation of basic (key) tasks fully satisfy these requirements (Khazankin, 1991, 2000). A key task is a basic task for solving another one, including non-standard mathematical problems. Key tasks are a minimum of tasks. Having mastered the methods of their solving, the student will be able to solve any problem on the topic. The selection of key tasks allows to intensify students' activity in solving mathematical problems and significantly reduce students' load (Viranovskaya, 2008).

\section{Research Methods}

To carry out the research, we used the following methods: analysis of scientific and methodological literature on the research topic, analysis and generalization of teachers' experience and our own experience in the system of secondary and higher education, analysis of students' educational activities and its results, development of didactic materials, diagnostic tools, interviews, questionnaires of students and teachers, pedagogical experiment.

\section{Aprobation, Generalization and Implementation of Research Results}

The authors of the research have carried out approbation, generalization and implementation of research results while working with students of 8-11 grades of schools and lyceums of the Kirov, Volga and Moscow regions, with students of 1-5 courses of the direction of training "Pedagogical education", Vyatka State University, Kazan (Volga region) Federal University, Sechenov and Lomonosov Moscow Universities, with teachers of mathematics of schools and lyceums:

- at the elective course "Tasks with parameters" in grades 10-11, the multidisciplinary lyceum of the city of Kirovo-Chepetsk, Kirov region (2016-2021); Lyceum of Natural Sciences of the city of Kirov (2016-2021) and Lyceum No. 21 of the city of Kirov (2016-2019) (72 hours in each class, more than 100 students annually);

- as part of studying disciplines "Equations and inequalities", "Methods of visualization in teaching mathematics", "Extracurricular work in mathematics" at Vyatka State University, Kazan (Volga region) Federal University, Sechenov and Lomonosov Moscow Universities (2016-2021) (30-40 students annually);
- as part of supervising the coursework and final qualifying work on the theory and methodology of teaching mathematics, a 5-year student of the direction of training Pedagogical education (with two profiles), profile Mathematics and computer science (2017-18, 2018-19).

- with teachers of mathematics as part of refresher courses (80-110 participants annually since 2016);

- in the form of reports and speeches at scientific conferences and seminars of various levels, including international ones, publications in collections of scientific articles and scientific and methodological periodicals.

The research had three stages.

At the first stage, we investigated the state of the problem in the theory and practice of teaching students. For this, we studied and analyzed psychologicalpedagogical and mathematical-methodological literature on the research problem, observed and analyzed working experience of mathematics teachers on the subject of teaching to solve problems with parameters containing the equation of a circle.

At the second stage, we worked out educational, methodological and didactic materials for teaching students to solve problems with parameters including the equation of a circle as part of special and elective courses. The implementation of educational, methodological and didactic materials was discussed through feedback with mathematics teachers, during reports at conferences and seminars at various levels. It made possible to consistently improve the proposed methodology.

During the third stage the authors and teachers of mathematics conduct experimental teaching and approbation of the proposed educational, methodological and didactic materials.

\section{RESULTS}

\section{Typology of Tasks with Parameters Including the Equation of a Circle}

To compile a typology of tasks with parameters, including the equation of a circle, we have analyzed a great amount of problems that were used for studying for several years. The analysis has shown that for solving such tasks, we should choose a graphical method which implies the construction of graphical images of equations, inequalities and/or their systems. Moreover, the analysis has made it possible to identify a wide range of lines/areas of the plane, which are combined with a circle in task conditions. Therefore, the basis of the typology is a combination of the equation of a circle and analytical expressions that define other lines/areas or their combinations on a plane. It has helped to single out basic knowledge and skills for each type of tasks, used in the process of solving them (Table 1 ). 
Table 1. Typology of tasks with parameters including the equation of a circle

I. Two circles Investigation of the relative position of two circles, $R$ и $r$ - radii, $d$ - distance between centers

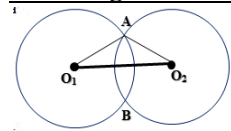

If $|R-r|<d<R+r$, then the circles intersect (have two common points)

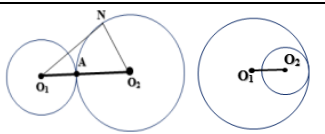

If $d=R+r$ or $d=|R-r|$, then

the circles touch (have one common point)

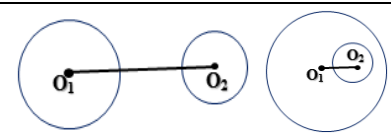

If $d>R+r$ or $d<|R-r|$, then the circles do not intersect (do not have common points)

II. A circle and $\quad-y-y_{0}=f(a)\left(x-x_{0}\right)$, where the multiplier $f(a)$ is the slope of the indicated straight lines, depending

line transformations on a plane on the parameter $a$, the set of straight lines on the coordinate plane, obtained from each other by turning by the appropriate angle relative to the point $\left(x_{0} ; y_{0}\right)$ - the center of rotation;

- $y=k x+f(a)$, where the term $f(a)$ is the free term of the equation, depending on the parameter $a$, is the set of straight lines on the coordinate plane, obtained from each other by parallel translation by the corresponding value $f(a)$ along the axis $O y$.

Studying the relative position of a circle and a straight line, $R$ - radius, $d$ - distance from the center of a circle to a straight line

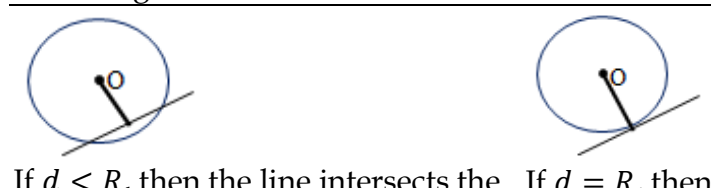

If $d<R$, then the line intersects the circle (have two common points)
If $d=R$, then the line touches the circle (have one common point)

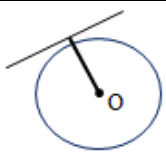

If $d>R$, then the line does not intersect the circle (do not have common points)

III. A circle and set - $a x+b y+c=0$, where $a^{2}+b^{2} \neq 0$ - equation of a straight line on the coordinate plane;

of straight lines $\left.\quad-a_{1} x+b_{1} y+c_{1}\right)\left(a_{2} x+b_{2} y+c_{2}\right)=0$, where $a_{i}{ }^{2}+b_{i}{ }^{2} \neq 0(i=1,2), \frac{a_{1}}{a_{2}} \neq \frac{b_{1}}{b_{2}}-$ two intersecting lines on the coordinate plane;

- $\left|a_{1} x+b_{1} y+c_{1}\right|=\left|a_{2} x+b_{2} y+c_{2}\right|$, where $a_{i}^{2}+b_{i}^{2} \neq 0(i=1,2), \frac{a_{1}}{a_{2}} \neq \frac{b_{1}}{b_{2}}$ - two intersecting lines on the coordinate plane;

- $|a x+b y+c|=m$, where $m>0, a^{2}+b^{2} \neq 0$, - two parallel lines on the coordinate plane;

- $\left|a_{1} x+b_{1} y+c_{1}\right|=a_{2} x+b_{2} y+c_{2}$, where ${a_{i}}^{2}+b_{i}{ }^{2} \neq 0(\mathrm{i}=1,2), \frac{a_{1}}{a_{2}} \neq \frac{b_{1}}{b_{2}}$ - set of corner points on a coordinate plane, excluding interior points

IV. A circle and a $\sqrt{\left(x-x_{1}\right)^{2}+\left(y-y_{1}\right)^{2}}+\sqrt{\left(x-x_{2}\right)^{2}+\left(y-y_{2}\right)^{2}}=\sqrt{\left(x_{2}-x_{1}\right)^{2}+\left(y_{2}-y_{1}\right)^{2}}$, where $x_{1}, x_{2}, y_{1}, y_{2}-$ the given line numbers, and $x_{1} \neq x_{2}$ и $y_{1} \neq y_{2}$ - the equation of the segment on the coordinate plane

V. A circle and an $y-y_{0}=k \cdot\left|x-x_{0}\right|$, where $k \neq 0-$ an "angle" on the coordinate plane with apex at a point $\left(x_{0} ; y_{0}\right)$ and an "angle" (polyline) axis of symmetry $x=x_{0}$

VI. A circle and a $-\left|a_{1} x+b_{1} y+c_{1}\right|+\left|a_{2} x+b_{2} y+c_{2}\right|=m$, where $m>0, a_{i}{ }^{2}+b_{i}{ }^{2} \neq 0(i=1,2), \frac{a_{1}}{a_{2}} \neq \frac{b_{1}}{b_{2}}-$ a parallelogram polygon equation on the coordinate plane;

- $\frac{\left|x-x_{0}\right|}{k}+\frac{\left|y-y_{0}\right|}{l}=1$, where $k>0, l>0$ - a rhombus with center $\left(x_{0} ; y_{0}\right)$, diagonals $d_{1}=2 k$ и $d_{2}=2 l$, respectively, parallel to the axes $O x$ and $O y$ on the coordinate plane;

- $|x|+|y|=k$, where $k>0-$ a square with a center $(0 ; 0)$, diagonal $d=2 k$, parallel to the axis $O x$ on the coordinate plane

VII. A circle and - a straight $a x+b y+c=0$, where $a^{2}+b^{2}>0$ splits the coordinate plane into two open half-planes so an area that the coordinates of the points of one half-plane satisfy the inequality $a x+b y+c>0$, and the other the inequality $a x+b y+c<0$;

- a circle $\left(x-x_{0}\right)^{2}+\left(y-y_{0}\right)^{2}=R^{2}$ divides the coordinate plane into two parts so that the coordinates of the points lying outside the circle satisfy the inequality $\left(x-x_{0}\right)^{2}+\left(y-y_{0}\right)^{2}>R^{2}$, and those located inside the circle satisfy the inequality $\left(x-x_{0}\right)^{2}+\left(y-y_{0}\right)^{2}<R^{2}$;

- $|a x+b y+c| \leq m$, where $m>0, a^{2}+b^{2} \neq 0$ - the set of interior points of the "strip" on the coordinate plane, including boundaries;

- $\left(a_{1} x+b_{1} y+c_{1}\right)\left(a_{2} x+b_{2} y+c_{2}\right) \leq 0$ or $\left.\left(a_{1} x+b_{1} y+c_{1}\right)\left(a_{2} x+b_{2} y+c_{2}\right) \geq 0\right)$, where $a_{i}{ }^{2}+b_{i}{ }^{2} \neq 0$ $(i=1,2), \frac{a_{1}}{a_{2}} \neq \frac{b_{1}}{b_{2}}$ - set of interior points of vertical corners on a coordinate plane, including boundaries;

- $\left|a_{1} x+b_{1} y+c_{1}\right| \leq\left|a_{2} x+b_{2} y+c_{2}\right|$, where $a_{i}^{2}+b_{i}^{2} \neq 0(i=1,2), \frac{a_{1}}{a_{2}} \neq \frac{b_{1}}{b_{2}}$ - set of interior points of vertical corners on a coordinate plane, including boundaries;

- $\left|a_{1} x+b_{1} y+c_{1}\right| \leq a_{2} x+b_{2} y+c_{2}$, where $a_{i}{ }^{2}+b_{i}{ }^{2} \neq 0(i=1,2), \frac{a_{1}}{a_{2}} \neq \frac{b_{1}}{b_{2}}$ - set of interior points of a corner on a coordinate plane, including boundaries 
Table 1 (continued). Typology of tasks with parameters including the equation of a circle

$\begin{array}{ll}\begin{array}{l}\text { VIII. A circle and } \\ \text { other lines }\end{array} & y=a x^{2}+b x+c\left(y=a\left(x-x_{0}\right)^{2}+y_{0}\right) \text {, where } a \neq 0-\text { a parabola on a coordinate plane with apex at a } \\ & \text { point }\left(x_{0} ; y_{0}\right) \text { and an axis of symmetry } x=x_{0} ;\end{array}$

Table 2. Interpretations of some equations of a circle containing the parameter $a$

\begin{tabular}{ll}
\hline$\left(x-x_{0}\right)^{2}+\left(y-y_{0}\right)^{2}=a^{2}$ & $\begin{array}{l}\text { a family of circles with a common center }\left(x_{0}, y_{0}\right) \text { of radius } R=|a| \text { (concentric circles) at } a \neq 0 \text {; if } \\
a=0, \text { then the equation defines a point }\left(x_{0}, y_{0}\right)\end{array}$ \\
\hline$\left(x-x_{0}\right)^{2}+\left(y-y_{0}\right)^{2}=a$ & $\begin{array}{l}\text { a family of circles with a common center }\left(x_{0}, y_{0}\right) \text { of radius } R=\sqrt{a} \text { (concentric circles) at } a>0 ; \text { if } \\
a=0, \text { then the equation defines the point }\left(x_{0}, y_{0}\right)\end{array}$ \\
\hline$(x-a)^{2}+(y-a)^{2}=R^{2}$ & a family of circles of the same radius $R$ centered $(a, a)$, on a straight line $y=x$ \\
\hline$(x-a)^{2}+\left(y-a^{2}\right)^{2}=R^{2}$ & a family of circles of the same radius $R$ centered $\left(a, a^{2}\right)$ on a parabola $y=x^{2}$ \\
\hline
\end{tabular}

\section{The Content of the Propaedeutic Stage in Teaching Students to Solve Tasks with Parameters, Including the Equation of a Circle}

We have already noted (Zdorovenko et al., 2016; Zdorovenko and Zelenina, 2018; Zelenina and Krutikhina, 2019) that the propaedeutic stage plays a significant role in successful teaching to solve tasks with parameters. The study helped to determine its content and formulate methodological recommendations for the implementation of this stage of training. One of the components of the propaedeutic stage is teaching students to construct geometric images of equations, inequalities with one (two) variables and/or their systems (the right column of Table 1). The basis of the system of tasks used in the framework of the special courses consists of exercises from the collection of tasks (Galitsky et al., 2001). An important component of the propaedeutic stage also works with the equation of a circle. First, students should develop the ability to bring the general equation of a circle to the canonical form, followed by the determination of the coordinates of its center and radius. Secondly, the issues of transforming a circle, the radius and/or coordinates of the center deserve special attention. Examples of some interpretations of the equation of a circle containing a parameter are given in Table 2.

As you can see from the last two columns of the table, one of the key is the ability to find the line of centers of a family of circles (in the case when the coordinates of the center depend on the parameter). If the line of the centers of circles is a straight line, students should know various ways to find its equation. The optimal way is the preparation of parametric equations of a straight line passing through two given points. For example, let us find the line of centers of a family of circles $(x-2 a+$ $2)^{2}+(y-3 a-1)^{2}=25$. The points that are the centers of a family of circles have coordinates $(2 a-2 ; 3 a+1)$. Hence, $x=2 a-2 ; y=3 a+1$ - parametric equations of the straight line containing these points. From the first equation we obtain $a=\frac{1}{2} x+1$. Substituting the expression for the parameter $a$ into the second equation, we have $y=\frac{3}{2} x+4$ - the line of the centers of the family of circles. If you give the parameter $a$ two specific values and obtain the coordinates of two points $\left(x_{1} ; y_{1}\right)$ and $\left(x_{2} ; y_{2}\right)$ belonging to the line of centers, to compose its equation, you can use the equation of a straight line passing through two points $\frac{x-x_{1}}{x_{2}-x_{1}}=\frac{y-y_{1}}{y_{2}-y_{1}}$ or solve a system of equations $\left\{\begin{array}{l}y_{1}=k x_{1}+b ; \\ y_{2}=k x_{2}+b\end{array}\right.$. Teaching to solve the above basic (key) tasks of the propaedeutic stage can be purposefully carried out both in lessons and extracurricular activities, and within the framework of a special course. As a result of the research, we have developed a program for such a course, didactic and methodological materials for it, including recommendations for using the program "Living Mathematics" to illustrate the transformations of figures on a plane. It is advisable to conduct most of the special course lessons in the form of laboratory work.

\section{Learning to Solve Basic (Key) Tasks on the Topic "Equation of a Circle in Tasks with Parameters"}

The typology of tasks presented above has determined the choice of basic (key) tasks on the topic. The combinations of the equation of a circle and other lines of the plane highlighted in the typology allow to assume that most of the tasks are reduced to the study of the relative position of a circle and a line (types II - VII). It is important to teach students to use algebraic and geometric solutions for this. Let the circle be given by the equation $\left(x-x_{0}\right)^{2}+\left(y-y_{0}\right)^{2}=R^{2}$, and the straight line by the equation $y=k x+b$, which is easily transformed to the form $A x+B y+C=0$ applying the geometric method. Basic reasoning schemes for solving the above problems are contained in Table 3.

Let us note that the above reasoning schemes can be the subject of discussion at the propaedeutic stage of teaching. It is enough to make pairs of equations of circles and lines and invite students to explore their mutual arrangement. The mathematical content of such exercises does not go beyond the scope of the program material for grades 8-9. Besides, if the equations of a 
Table 3. Methods for studying the relative position of a circle and a straight line

\begin{tabular}{l} 
The relative \\
position of a circle \\
and a straight line \\
\hline $\begin{array}{l}\text { A circle and a straight line } \\
\text { have two points in } \\
\text { common (a straight line } \\
\text { intersects a circle) }\end{array}$
\end{tabular} $\begin{aligned} & \begin{array}{l}\text { Let us compose a system of equations } \\
\left(x-x_{0}\right)^{2}+\left(y-y_{0}\right)^{2}=R^{2}, \\
y=k x+b\end{array} \\
& \text { have two solutions. Solving it by the } \\
& \text { substitution method, we get a quadratic } \\
& \text { equation, which, in turn, must also have } \\
& \text { two roots. For this, it is necessary and } \\
& \text { sufficient that its discriminant be positive } \\
& (D>0) .\end{aligned}$

A circle and a straight line Let us compose a system of equations have one point in common $\left\{\left(x-x_{0}\right)^{2}+\left(y-y_{0}\right)^{2}=R^{2}\right.$, that should (the straight line touches the circle)

points in common
Geometric solution

The distance from the center of a circle, a point $O\left(x_{0} ; y_{0}\right)$ to a straight line $A x+B y+C=0$ is less than the radius of a circle $R$. Using the formula for the distance from a point to a straight line, we compose an inequality $\frac{\left|A x_{0}+B y_{0}+C\right|}{\sqrt{A^{2}+B^{2}}}<R$. In order for a straight line and a circle to have exactly two common points, it is necessary and sufficient that the numerical inequality obtained as a result of the transformations turns out to be true.

The distance from the center of a circle - the point $O\left(x_{0} ; y_{0}\right)$ to a straight line $A x+B y+C=0$ is equal to the radius of a circle $R$. Using the formula for the distance from a point to a straight line, we compose an equality $\frac{\left|A x_{0}+B y_{0}+C\right|}{\sqrt{A^{2}+B^{2}}}=R$. In order for a straight line and a circle to have exactly one common point, it is necessary and sufficient that the numerical equality obtained as a result of the transformations turns out to be true.

The distance from the center of a circle - a point $O\left(x_{0} ; y_{0}\right)$ to a straight line $A x+B y+C=0$ is greater than the radius of a circle. Using the formula for the distance from a point to a straight line, we compose an inequality $\frac{\left|A x_{0}+B y_{0}+C\right|}{\sqrt{A^{2}+B^{2}}}>R$. In order for the line and the circle to have no common points, it is necessary and sufficient that the numerical inequality obtained as a result of the transformations turns out to be true. circle and/or a straight line contains a parameter $a$, the reasoning given in Table 3 makes it possible to compose equations/inequalities with respect to $a$ and, as a result of their solution, obtain an answer to the question of the relative position of a circle and a straight line depending on the parameter values. Our experience with students shows that the most common case is that a circle and a straight line are touched. This allows to consider the basic (key) task of finding the parameter values at which the circle and the straight line are in the tangency position. Let us illustrate it with an example of various ways of finding the parameter $a$ values for which a circle and a straight line have only one common point.

Task. Find all values of $a$ for each of which the system of equations $\left\{\begin{array}{l}x^{2}+5 x+y^{2}-y-|x-5 y+5|=52 \text {, has } \\ y-2=a(x-5)\end{array}\right.$ exactly two solutions.

Decision. Let us draw on the coordinate plane a set of points, whose coordinates satisfy the first equation of the system.

\section{Consider two cases:}

1) If $x-5 y+5 \geq 0$, then we obtain the equation

$$
x^{2}+5 x+y^{2}-y-x+5 y-5=52
$$

$$
\begin{aligned}
& \Leftrightarrow x^{2}+4 x+y^{2}+4 y-57=0 \\
& \Leftrightarrow \Leftrightarrow(x+2)^{2}+(y+2)^{2}=65 .
\end{aligned}
$$

The obtained equation defines a circle centered at a point $O_{1}(-2 ;-2)$ of radius $R=\sqrt{65}$.

2) If $x-5 y+5 \leq 0$, then we obtain the equation

$$
\begin{gathered}
x^{2}+5 x+y^{2}-y+x-5 y+5=52 \\
\Leftrightarrow x^{2}+6 x+y^{2}-6 y-47=0 \\
\Leftrightarrow(x+3)^{2}+(y-3)^{2}=65 .
\end{gathered}
$$

The last equation defines a circle centered at a point $\mathrm{O}_{2}(-3 ; 3)$ with a radius $R=\sqrt{65}$.

The resulting circles intersect at two points $A(-10 ;-1)$ and $B(5 ; 2)$ and lie on a straight line $x-5 y+5=0$, therefore, in the first case, we obtain an arc $\omega_{1}$ with ends at points $A$ and $B$, in the second, an arc $\omega_{2}$ with ends at the same points.

Consider the second equation of the system. It defines a straight line passing through a point $B(5 ; 2)$ with a slope $a$ that takes all possible values. It is convenient to imagine a "moving" line that "revolves" around a point $B(5 ; 2)$. Mentally rotating a straight line $y=a(x-5)+$ 2 , we determine its positions when it has exactly two points in common with the arcs $\omega_{1}$ and $\omega_{2}$. Figure 1 


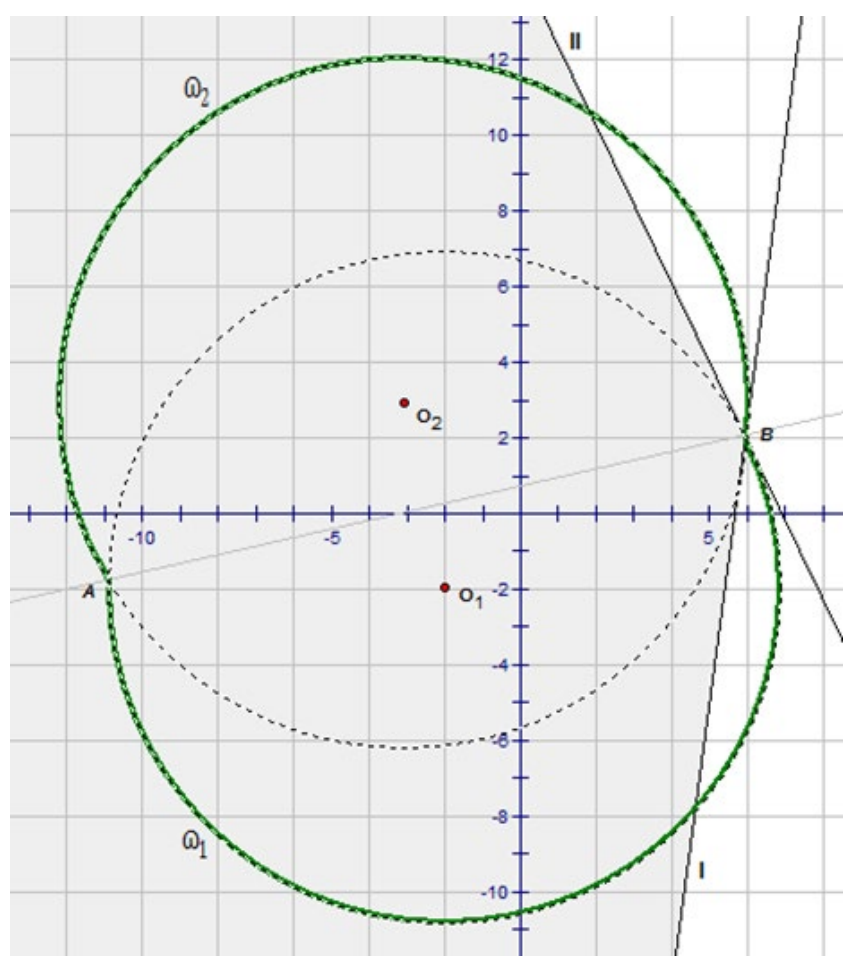

Figure 1. Drawing to the solution of the problem

highlights an area (including boundaries), where direct populations $y=a(x-5)+2$ must lie for this condition to be satisfied. Find values a corresponding to the positions of the lines that bound the selected area.

I. The straight line $y=a(x-5)+2$ touches an arc $\omega_{1}$ of a circle centered at the point $O_{1}(-2 ;-2)$ of the radius $R=\sqrt{65}$. Let us explore this touch in three ways.

The first way is algebraic. Let us compose a system of equations $\left\{\begin{array}{c}(x+2)^{2}+(y+2)^{2}=65, \\ y=a(x-5)+2\end{array}\right.$ and require it to have a unique solution. Substituting the expression for $y$ into the first equation of the system, after transformations, we obtain a quadratic equation $\left(a^{2}+\right.$ 1) $\cdot x^{2}-\left(10 a^{2}+2 a-6\right) \cdot x+25 a^{2}+10 a-55=$ $0\left(a^{2}+1 \neq 0\right.$ under no values $\left.a\right)$, which has a single root if its discriminant $D=4\left(a^{2}-16 a+64\right)=4(a-8)^{2}$ is zero. We get that $D=0$ at $a=8$. Thus, the straight line touches the arc at $a=8$. Note that the great advantage of this method of reasoning is its availability from the point of view of the program material (8th grade). The disadvantage is that the algebraic way of solving leads to rather cumbersome identical transformations (for example, when finding the discriminant), which take a lot of time and lead to technical errors.

The second way is geometric. Let us express the distance from the center of a circle - the point $O_{1}(-2 ;-2)$ to a straight line $y=a(x-5)+2$ and equate it to the radius of the circle. The equation for the parameter $a$ is $\frac{|a(-3-5)+2-3|}{\sqrt{a^{2}+1}}=\sqrt{65}$. Then $|-8 a-1|=\sqrt{65 \cdot\left(a^{2}+1\right)}$. Both sides of the equation are non-negative; raise them to the second power. We will get $64 a^{2}+16 a+1=$ $65 a^{2}+65$. Hence $a^{2}-16 a+64=0$ and $a=8$. Note that this method of reasoning is more concise and technically simpler than the first, but it requires students to deeply understand the situation, some special knowledge and skills. So, it is compulsory for students to be able to write down the general equation of a straight line, that is, to move from an equation with a slope $y=a(x-5)+2$ to an equation $a x-y-5 a+2=$ 0 which allows further to use the formula for finding the distance from a point to a straight line. The equation obtained is not standard for school mathematics and requires students to choose the most rational way to solve.

The third way is based on the application of the ratio between the slopes of mutually perpendicular straight lines. It was previously noted that the tangent point $B$ belongs to a circle. Let us draw the radius $O_{2} B$, which is perpendicular to the tangent, that is, the straight line $y=$ $a(x-5)+2$, the slope of which is equal to $a$. Let us make the equation of a straight line $\mathrm{O}_{2} B$, using the equation of a straight line passing through two given points $\left(O_{2}(-3 ; 3)\right.$ and $\left.B(5 ; 2)\right): \frac{x+3}{5+3}=\frac{y-3}{2-3}$. Hence, $y=$ $-\frac{1}{8} x+\frac{21}{8}$, where the slope is equal $-\frac{1}{8}$. Knowing that the slope of mutually perpendicular straight lines are reciprocal in magnitude and opposite in sign, we obtain $a=8$. This solution method, as we see, is also fairly concise, basic knowledge and skills are obvious.

So, in position $\mathrm{I}$, the line of the aggregate $y=a(x-$ $5)+2$ has a slope equal to 8 . Carrying out the same reasoning for position II, we obtain $a=-\frac{7}{4}$. Thus, between positions I and II, the parameter $a$ takes values from $-\frac{7}{4}$ to 8 . Consequently, the condition of the problem is satisfied by $-\frac{7}{4} \leq a \leq 8$, for which the system has two solutions. For $a<-\frac{7}{4}$ and $a>8$ each line of the collection $y=a(x-5)+2$ intersects each of the arcs $\omega_{1}$ and $\omega_{2}$ at a point $B$ and one more point different from $A$. That is, the original system has three solutions. The answer is: $-\frac{7}{4} \leq a \leq 8$.

The methodological value of the problem under consideration lies in the fact that its condition allows students to demonstrate various ways of solving the basic (key) task, which is not always possible in other problem situations. The following task can be proposed for self-solution in order to consolidate the knowledge and skills discussed above It has all the above characteristics, but differs in its geometric way.

Task. Find all values of $a$ for the system of equations $\left\{\begin{array}{c}2 x-2 y-2=x^{2}+y^{2}-1 \mid, \\ y=a(x-1)\end{array}\right.$ to have more than two solutions. Answer: $1<a<2$.

When students master ways to solve basic (key) tasks on the topic "Equation of a circle in tasks with parameters", it is the first and integral stage. At the next stage, on the basis of the typology compiled during the study, a special system of tasks is constructed more than 
Table 4. The results of students' diagnostic work (9th grade)

Content block Main types of tasks

Percentage of students

building a graphical image of an equation with one (two) variables;
who completed the task

building a graphical image of an equation with one (two) variables; correctly, \%

Graphical images of building a graphical image of inequality with one (two) variables;

93.4

equations, inequalities with two variables and or their systems

building a graphical image of a system of equations with one (two) variables;

80.3

building a graphical image of a system of inequalities with one (two) variables;

90.8

building a graphical image of a mixed system with one (two) variables

77.6

reduction of the general equation of the circle to the canonical form and finding

81.6

coordinates of the center of the circle and its radius;

construction of circles, the radius of which is an irrational number;

Circle transformations finding coordinates of the center and/or the radius of the circle, depending on on a plane the parameter;

reduction of the general equation of a circle, the center and/or radius of which depend on the parameter, to the canonical form;

finding the line of centers of circles;

Investigation of the relative position of a
circle and a straight line on a plane

in a geometric way;

93.4

using the ratio between the slopes of mutually perpendicular straight lines

40.8

50 tasks), which makes it possible to teach according to the plan and purpose and, which is very important, it allows students to work in a self-education mode, since the material is well structured and methodically processed. Such an organization of work with problem material allows students to successfully apply the knowledge and skills acquired to solve a fairly wide range of tasks.

\section{Results of the Experimental Part of the Study}

During the experimental part of the research in 20182019, we carried out the approbation of didactic and methodological materials for the propaedeutic stage of teaching students to solve tasks with parameters, including the equation of a circle. The approbation covered 76 students of the 9th grade of schools in the city of Kirov and the Kirov region, who planned to take the unified state exam in mathematics at the profile level at the 11th grade (the average annual grade in mathematics for grade 8 is 4.68 points). A 5 th year student (direction of training Pedagogical education (with two profiles), profile Mathematics and computer science) prepared sets of tasks for three content blocks under our leadership as part of her coursework and final qualifying work on the theory and methodology of teaching mathematics. The blocks were: 1) graphic images of equations, inequalities with one (two) variables and/or their systems, 2) transformations of a circle on a plane, 3) the relative position of a circle and a straight line on a plane. Classes ( 34 hours) were a part of a special course in the form of practical and laboratory work. To conduct laboratory workshops, we used the software complex "Living Mathematics", which allowed by means of customized animation of objects to study transformations of a circle and the relative position of a circle and a straight line on a plane. A 5th year student, teachers of schools in the city of Kirov and the Kirov region took part in the classes. During and at the end of the special course, we carried out diagnostic and tested students' work. A final discussion of the results with colleagues has shown the following. In general, the developed didactic and methodological materials correspond to the goals of the propaedeutic stage. In addition, during distance learning due to the epidemiological situation since spring 2020, didactic materials given to students have given them the opportunity to self-education. This made it possible to complete the program of the special course. The main difficulties for the students and, as a result, erroneous decisions were caused by the following tasks: construction of graphic images of inequalities, systems of inequalities, mixed systems (the first content block) on the plane; reduction of the general equation of a circle, the center and radius of which depend on the parameter, to the canonical form (the second content block); investigation of the relative position of a circle and a straight line in a geometric way and using the relationship between the slopes of mutually perpendicular straight lines (the third content block). Table 4 presents the results of students' diagnostic work.

The results of a questionnaire survey of 9th-students, which we conducted at the end of the special course, showed that the proposed tasks aroused their interest. It is evidenced by the following value judgments of students: the tasks are unusual and interesting, differ from tasks in school textbooks; tasks are surprising as it is possible to build not only graphs of school functions, but also equations and even inequalities; we learned a lot 
Table 5. Points received by students for solving tasks of the final diagnostic work

\begin{tabular}{cccccc|cccccc|ccccc|cccccc}
\hline \multirow{2}{*}{ Student group } & \multicolumn{1}{c}{ Task №1 № } & \multicolumn{1}{c}{ Task №2 №3 } & \multicolumn{1}{c}{ Task №4 } \\
\cline { 2 - 5 } & 4 & 2 & 1 & 0 & 4 & 3 & 2 & 1 & 0 & 4 & 3 & 2 & 1 & 0 & 4 & 3 & 2 & 1 & 0 \\
\hline Group 1 (33 students) & 17 & 1 & 8 & 7 & 0 & 15 & 0 & 10 & 5 & 3 & 15 & 0 & 9 & 8 & 1 & 12 & 1 & 10 & 7 & 2 \\
Group 2 (36 students) & 14 & 0 & 7 & 10 & 2 & 11 & 2 & 5 & 8 & 7 & 10 & 0 & 12 & 9 & 2 & 5 & 0 & 7 & 17 & 4 \\
Group 3 (32 students) & 12 & 0 & 5 & 14 & 3 & 12 & 0 & 5 & 11 & 5 & 11 & 0 & 3 & 11 & 8 & 0 & 0 & 0 & 0 & 0 \\
\hline
\end{tabular}

of new things; we thought that the circle was only in geometry, but it turned out to be in algebra. We would like to especially note students' positive assessment of lessons in the form of laboratory work using the "Living Mathematics" software package. Students highly appreciated the clarity of the material, the ability to use a computer program to check the solutions of tasks obtained independently (including during distance learning).

The next stage of approbation of the results obtained took place in 2020-21. Groups of students of two categories took part in the experimental teaching: students of grade 10 - participants of the propaedeutic stage of teaching in 2018-19 (33 students, the average annual grade in mathematics for grade 9 is 4.63 points) group 1 , and newly recruited students of grade 10 who were enrolled in a two-year special course "Tasks with parameters" to prepare for the final certification in mathematics at the profile level (36 students, the average annual grade in mathematics for grade 9 is 4.71 points) group 2. Classes (72 hours) were conducted during the academic year by the authors of the article in the schools of the city of Kirov and the Kirov region. The subject of observation was teaching students to solve problems with parameters containing the equation of a circle in terms of confirming the feasibility of introducing the methodology for studying the topic "Equation of a circle in tasks with parameters", based on identifying basic (key) tasks and assessing the role of the propaedeutic stage of studying the topic. Classes had two forms lectures, the main purpose of which was to teach how to solve basic (key) tasks on the topic, and workshops, where students solved problems corresponding to the above typology. We have underlined that purposeful work with basic (key) tasks was a prerequisite for conducting classes on the above topic. The ability to solve such problems after a certain stage of teaching was diagnosed with the subsequent correction of knowledge. The order of presenting tasks to students in accordance with the typology was also determined. This is important, since the results of the final diagnostic work on the topic "Equation of a circle in tasks with parameters" of the students of 2020-21 have been compared with the results of the same work carried out as part of the special course in 2018-19, where the indicated technique was not applied - (32 students, the average annual grade in mathematics for grade 9 is 4.67 points) - group 3. Diagnostic work included tasks containing the equation of a circle, proposed in different years at the state exam. The solution was assessed from
0 to 4 points in accordance with the criteria for evaluating this task at the state final exam. Since the number of groups was approximately the same, we did not give the percentage of the number of students who received this or that number of points. Table 5 shows the results of the final diagnostic work.

Thus, the results obtained allowed us to draw the following conclusions. The highest was the success of solving tasks of the final diagnostic work in group 1. This is largely due to the propaedeutic teaching of students of this group. The participants in group 2 were less successful. The table shows that a fairly large number of solutions were estimated at 1 point. This means that students stopped their solution on building a graphical image of the system of equations and did not advance further, because without propaedeutic preparation they lost time on translating the problem statement from algebraic language to geometric language. The participants in group 3 did not start solving problem no. 4 (the same for all groups). According to our observations in group 1 on the topic "Equation of a circle in tasks with parameters", the number of solved problems for the period of studying the topic was about $30 \%$ more than in group 2. That is, the applied methodology made it possible to intensify the process of studying.

\section{DISCUSSIONS}

The study has shown that issues related to teaching students to solve tasks with parameters are widely discussed in the scientific and methodological literature. However, there are no works that offer a complete and methodically structured material on certain topics, including the topic "Equation of a circle in tasks with parameters". Our long-term observations of students have shown that the propaedeutic stage of work in grades 8-9 has a great positive effect on studying this topic. The content of this stage developed by us does not contradict the program material and its assimilation has a great positive effect on the development of students' ability to solve tasks with parameters of the specified type. The allocation of reference problems on the topic and their application to solve a specially designed system of tasks also has a great positive effect. The last two aspects make it possible to successfully implement one of the basic principles of didactics "from simple to complex". Teachers of mathematics from the city of Kirov and the Kirov region, involved in the implementation of the developed methodology, note that the materials worked out during the study can 
significantly speed up the preparation for classes on the topic, quickly fill gaps in mathematical education of a high level of complexity. Students attending the special course and students who used the course materials at the university, give a positive assessment of teaching materials from the point of view of organizing selfeducation on the topic. Thus, our didactic and methodological materials can become the basis of elective courses, course preparation as part of the advanced training of mathematics teachers, subject training of students - future teachers in the subject, and students' textbooks.

\section{CONCLUSION}

Based on the analysis of scientific and methodological literature, own experience in teaching mathematics, we have developed and implemented a methodology for teaching the solution of tasks with parameters that includes the equation of a circle. Longterm experience of working with students shows that such problems cause great difficulties, since they require students to master the material of school mathematics at a sufficiently high level. On the other hand, the equation of a circle is often part of competitive tasks with a parameter, since it has a great intra-subject potential and, as a consequence, diagnostic value. Overcoming difficulties in teaching students to solve problems with parameters containing the equation of a circle is facilitated by using our methodology, the main provisions of which are the following. The importance of the propaedeutic stage, as its purpose to form the ability to build graphical images of equations, inequalities and their systems, graphs of functional dependencies, to explore the relative position of the circle and other lines of the plane. Teachers can implement this stage in mathematics classes in grades 8-9. A specially designed system of problems, compiled in accordance with the typology of tasks with parameters, including the equation of a circle. The typology is based on various combinations of the circle equation and analytical expressions that define other lines/areas or their aggregate on a plane. Allocation of basic tasks on the topic "Equation of a circle in tasks with parameters" and teaching students various ways to solve them. The results of the experimental work has shown that the use of the developed methodology in the classroom has a positive effect on the quality of teaching in solving problems containing the equation of a circle, contributes to a faster and better assimilation of educational material, including self-education.

\section{RECOMMENDATIONS}

The materials of the article can be useful for teachers of mathematics, teachers of additional mathematical education, teachers of higher educational institutions who are interested in significantly increasing the level of students educational achievements, teaching them to solve problems in mathematics of a competitive level. The way to improve the proposed methodology is to supplement it with new sets of tasks in accordance with the proposed typology, develop a set of laboratory works for students in grades 8-9.

Author contributions: All authors have sufficiently contributed to the study, and agreed with the results and conclusions.

Funding: This paper has been supported by the Kazan Federal University Strategic Academic Leadership Program.

Declaration of interest: No conflict of interest is declared by authors.

\section{REFERENCES}

Al-Hilli, W. H. (2019). Using software's and technology in solving mathematics problem to motivate and accelerate the learning process. Eurasia Journal of Mathematics, Science and Technology Education, 15(3), em1670. https:/ / doi.org/10.29333/ejmste/102421

Arcavi, A. (2003). The role of visual representations in the learning of mathematics. Educational Studies in Mathematics, 52(3), 215-241. https://doi.org/ 10.1023/ A:1024312321077

Aryutkina, S. V. (2002). Formation of generalized methods of solving equations and inequalities with parameters among students of grades 8-9 (PhD thesis), Arzamas.

Bashmakov, M. I. (1976). Equations and inequalities. Nauka.

Bhagat, K. K., \& Chang, C.-Y. (2015). Incorporating GeoGebra into geometry learning-A lesson from India. Eurasia Journal of Mathematics, Science $\mathcal{E}$ Technology Education, 11(1), 77-86. https:/ / doi.org/ 10.12973/eurasia.2015.1307a

Boukhanov, G. V., Vrublevskiy, A. S., Kosolapova, N. V., \& Martynova, E. V. (2019). Project activity as a technology implementation of the competencebased approach in modern educational process. Vestnik NCBŽD, 1(39), 26-32.

Dalinger, V. A. (1999). Formation of students' visual thinking in the process of teaching mathematics. Publishing house of OmGPU.

Dorofeev, G. V. (1983). On the compilation of cycles of interrelated problems. Mathematics at School, 6, 3439.

Dorofeev, G. V., Potapov M. K., \& Rozov, N. Kh. (1999). Mathematics. For applicants to universities. Bustard.

Galitsky, M. L., Goldman, A. M., \& Zvavich, L. I. (2001). Collection of problems in algebra for grades 8-9: textbook. Manual for students of school and classes with in-depth studying mathematics (7th ed.). Education.

Galiullina, E. R. (2018). Mastering the methods of generating ideas as a way to develop creativity. Vestnik NCBŽD, 1(35), 12-15.

Golubev, V. I. (1991). The absolute value of a number in competitive exams in mathematics. Quantor. 
Golubev, V. I. (2007). Solving complex and non-standard problems in mathematics. Ileksa.

Halomizer, A. Ya. (1987). On the experience of the teacher R.G. Khazankin. Mathematics at School, 4, 1621.

Karasev, V. A., \& Levshina, G. D. (2012). Solving tasks with parameters using graphs of functions. Ileksa.

Khazankin, R. G. (1991). Ten commandments of the teacher of mathematics. Public Education, 1, 70-73.

Khazankin, R. G. (2000). Mathematical education and secondary school. Mathematical education. Journal of the Foundation for Mathematical Education, 4(13), 1226.

Klekovkin, G. A., \& Maksyutin, A. A. (2009). Problemsolving approach in teaching mathematics. Era.

Kolyagin, Yu. M. (1977). Problems in teaching mathematics. Education.

Koryanov A. G., \& Prokofiev A. A. (2011). Using the method of visual-graphic interpretation when solving equations and inequalities with parameters. Mathematics at School, 1, 25-32.

Kovaleva, G. I., \& Dyumina T. Yu. (2009). Teaching future mathematics teachers to construct systems of problems by the "key" method. Bulletin of the Volgograd State Pedagogical University, 1, 139-143.

Kozhukhov, S. K., \& Kozhukhova, S. A. (2010a). Equations and inequalities with a parameter. OIUU.

Kozhukhov, S. K., \& Kozhukhova, S. A. (2010b). On the methodological expediency of solving problems in different ways. Mathematics at School, 3, 42-44.

Kozko, A. I., \& Chirsky, V. G. (2007). Tasks with a parameter and other complex problems. MTsNMO.

Krupich, V. I. (1995). Theoretical foundations of teaching the solution of school mathematical problems. Prometheus.

Litvinenko, V. N., \& Mordkovich, A. G. (1983). Workshop on solving problems in school mathematics. Algebra. Education.

Markov, V. K. (1970). Method of coordinates and tasks with parameters. Education.

Miroshin, V. V. (2008). Formation of a contentmethodological line of tasks with parameters in the course of mathematics at school (PhD thesis), Moscow.

Modenov, V. P. (2002). Mathematics for students and applicants. Institute for Computer Research.

Modenov, V. P. (2007). Tasks with parameters. Coordinateparametric method: a tutorial. Examination.

Olekhnik, S. N., Potapov, M. K., \& Nesterenko, Yu. V. (1992). Competition problems in mathematics. Nauka.

Osipenko, L. A., \& Statsevichute, E. E. (2010). Reference tasks in planimetry: a methodological guide. Irkutsk.

Ostanov, K., Inatov, A., \& Khimmatov, I. (2018). The role of the system of key problems in the process of teaching mathematics. European research: innovation in science, education and technology Collection of scientific articles XLI International scientific and practical conference (pp. 67-76). Problems of Science.

Rozov, N. Kh. (1997). Differentiated learning and problems of forming a "basis" in the space of tasks. Mathematical education: traditions and modernity: Abstracts of reports (pp. 67-68). Federal research and practical conference. NGPU.

Sarantsev, G. I. (1995). Exercises in teaching mathematics. Education.

Sarantsev, G. I. (2002). Methods of teaching mathematics in secondary school. Education.

Sergeev, I. N. (2005). Mathematics. Problems with answers and solutions. KDU.

Sharygin, I. F. (2000). Discourses on the concept of school geometry. MTsNMO.

Shestakov, S. A., \& Yurchenko, E. V. (1993). Equations with a parameter. Syllable.

Shivrinskaya, E. V. (2002). Tasks with parameters as a means of increasing the motivation of teaching mathematics (PhD thesis), Moscow.

Swetz, F. J., \& Chi, A. Y. (1983). Mathematics entrance examinations in chinese institutions of higher education. Educational Studies in Mathematics, 14(1), 39-54. https:/ / doi.org/10.1007/BF00704701

The concept of the development of mathematical education in the Russian Federation (2013). Rossiyskaya Gazeta. 2013. December, 27. http:/ / www.rg.ru/2013/12/27/matematika-sitedok.html

Tokareva, V. A., \& Zelenina, N. A. (2016). Laboratory work using the "Living Mathematics" program when teaching students in grades 7-8 to solve problems with a parameter. Scientific and methodological electronic journal "Concept", 9, 91-95. http:/ / e-koncept.ru/2016/46165.htm

Tolpekina, N.V. (2002). Methodology for organizing educational research in teaching students to solve equations, inequalities and systems with parameters (PhD thesis), Omsk.

Vazhenin, Yu. M. (1997). A self-instruction manual for solving tasks with parameters. USU.

Viranovskaya, E. V. (2008). Methods of teaching mathematics. ORGTI.

Wassie, Y. A., \& Zergaw, G. A. (2019). Some of the Potential Affordances, Challenges and Limitations of Using GeoGebra in Mathematics Education. Eurasia Journal of Mathematics, Science and Technology Education, 15(8), em1734, https://doi.org/10.29333/ejmste/108436

Yastrebinetskiy, G. A. (1986). Tasks with parameters. Education.

Zakirova, V. G., Zelenina, N. A., Smirnova, L. M., \& Kalugina, O. A. (2019). Methodology of teaching 
graphic methods for solving problems with parameters as a means to achieve high mathematics learning outcomes at school. Eurasia Journal of Mathematics, Science and Technology Education, 15(8), em1741. https:/ / doi.org/10.29333/ejmste/108451

Zdorovenko, M. Yu., Zelenina, N. A., \& Krutikhina, M. V. (2016). Using various methods for solving tasks with parameters at the Unified State Exam in mathematics / Scientific and methodological electronic journal "Concept", 8, 139-150. http://ekoncept.ru/2016/16176.htm

Zdorovenko, M.Yu., \& Zelenina N.A. (2018). Change of a variable in tasks with parameters. Scientific and methodological electronic journal "Concept", 7, 82-92. http:/ / e-koncept.ru/2018/186066.htm

Zelenina, N. A., \& Krutikhina, M. V. (2018). Problems of preparing students for final certification in the context of the results of the USE in mathematics in 2017 in the Kirov region. Scientific and methodological electronic journal "Concept", 3, 12-24. http://ekoncept.ru/2018/181011.htm

Zelenina, N. A., \& Krutikhina, M. V. (2019). Teaching students of grades 8-9 graphic methods to solve tasks with parameters. Mathematical Bulletin of Pedagogical Universities and Universities of the VolgaVyatka Region, 21, 253-259.
Zelenina, N. A., \& Krutikhina, M. V. (2021). Some problems of preparing students for final certification in the context of the results of the USE in mathematics in 2020 in the Kirov region. Management of the quality of education: problems and prospects: Materials of the All-Russian scientific and practical conference (10 -11 December 2020). - Ulyanovsk: Federal State Budgetary Educational Institution of Higher Education "UlGPU named after I.N. Ulyanov", pp. 37-44.

Zelenina, N. A., \& Nosova, N. V. (2020). Analysis of the Unified State Exam Results in the subject "Mathematics". Unified State Exam in the Kirov Region. Analysis of the results of the exam 2020: a collection of information, analytical and methodological materials. KGOAU DPO "IRO of the Kirov region.

Zharko, L. N. (2020). Case-study as an innovative pedagogical technology in teaching activities of lecturer of additional professional education. Vestnik NCBŽD, 2(44), 49-56.

Zilberberg, N. I. (1988). Introduction to mathematical creativity. Bashkir book publishing house.

Zilberberg, N. I. (1995). A lesson in mathematics: preparation and delivery. A book for a teacher. Education.

\section{http://www.ejmste.com}

